\title{
O DIREITO A TER DIREITOS COMO REALIZAÇÃO POLÍTICA PARA OS DIREITOS HUMANOS NA OBRA DE HANNAH ARENDT
}

\section{HE RIGHT TO HAVE RIGHTS AS A HUMAN RIGHTS POLICY IN HANNAH ARENDT'S WORK}

\author{
Aline Soares Lopes ${ }^{*}$ \\ Amélia do Carmo Sampaio Rossi ${ }^{* *}$
}

\begin{abstract}
RESUMO
O presente artigo, com o auxílio do método histórico dialético, tem o objetivo de analisar o significado da expressão "direito a ter direitos" que aparece na crítica da filósofa Hannah Arendt à execução dos direitos humanos. Ao realizar um estudo sobre as origens do totalitarismo, Arendt apresenta como os direitos humanos eram percebidos no mundo do entre-guerras, que deu início às desnacionalizações em massa, criando o grupo sintomático do mundo reconhecidos como apátridas. Para que os direitos humanos aconteçam será sempre preciso dar um passo além de considera-los apenas como leis universais, abstratas e inalienáveis. A ideia de concebê-los como uma ação política que deve sempre ser reiterada pela humanidade, aponta para um caminho melhor na perspectiva de realizá-los de forma mais concreta.
\end{abstract}

Palavras-chave: Direito a ter direitos. Apátridas. Refugiados.

\begin{abstract}
This article, with the help of the dialectical historical method, aims to analyze the meaning of the expression "right to have rights" that appears in the criticism of the philosopher Hannah Arendt to the implementation of human rights. In conducting a study of the origins of totalitarianism, Arendt presents how human rights were perceived in the interwar period, which initiated mass denationalization, creating the symptomatic group of the world recognized as stateless. For human rights to take place, it will always be necessary to take a step foward besides considering them only as universal, abstract and inalienable laws. The idea of conceiving them as a political action that must always be reiterated by humanity, points to a better path in the perspective of achieving them in a more concrete way.
\end{abstract}

Keywords: Right to have rights. Stateless. Refugees.

\footnotetext{
“Possui graduação em Direito pela Universidade Estadual de Ponta Grossa, Mestrado em Direitos Humanos e Políticas Públicas pela Pontifícia Universidade Católica do Paraná.

"* Possui graduação em Direito pela Universidade Federal do Paraná, Mestrado em Direito pela Universidade Federal do Paraná e Doutorado pela Universidade federal do Paraná. Atualmente é Professora Titular da Pontifícia Universidade Católica do Paraná.
} 


\section{INTRODUÇÃO}

Hannah Arendt é uma pensadora marcante e atual na abordagem do tema direitos humanos. Isto porque parte de sua obra dedicou-se a refletir o fracasso dos direitos humanos na segunda guerra mundial e posteriormente o surgimento de grandes massas de refugiados e deslocados de guerra, aliados por excelência ao conceito de direitos.

A instabilidade política e econômica na Europa do entre-guerras propiciou um terreno de preconceitos contra etnias minoritárias dentro dos mais novos soberanos Estados-nação. Para que a ideologia de um Estado forte e homogêneo fosse preservada, algumas comunidades, que não encaixavam-se nessa homogeneidade idealizada, sofreram consequências. Tais pessoas foram transformadas em uma espécie de inimigos objetivos para os Estados em crise, que em busca da criação de uma identidade, optaram por desprezar o "outro", o diferente. A identidade foi criada por meio da exclusão.

No auge do pensamento moderno a burocracia foi concebida como importante ferramenta do Estado-nação e prontamente utilizada na questão desses não-cidadãos, que não faziam parte da tríade Povo-Estado-Nação. Por meio de novas leis, massas perderam sua nacionalidade, muitos foram deportados, e não puderam encontrar algum lugar onde pudessem contar com os ditos direitos humanos, já que um apátrida ou uma pessoa sem Estado, não tem direitos, pelo simples fato de que não tem leis feitas em seu nome e para a sua proteção como parte do Estado, ou algum Estado que se interesse em lhe proteger.

O tema abordado por Arendt ainda é um tema atual visto a crise humanitária que assola o mundo. Crescem todos os dias nos noticiários casos de deslocados de guerra sem a possibilidade de encontrar um lugar para reestabelecer seus laços comunitários. Este cenário devolve a questão da efetividade dos direitos humanos. Afinal por que teóricos, políticos, sociólogos e principalmente ativistas continuam a invocar os direitos humanos tendo em vista sua inaplicabilidade e em determinados casos gerando até mesmo momentos de contradição, como as guerras pela paz.

Este artigo objetiva apontar, com o uso do método histórico dialético e tomando como referencial teórico Hannah Arendt, a possibilidade de um diálogo sobre a temática, apresentando as críticas do desenvolvimento do paradigma dos direitos humanos e retomando a responsabilidade de toda a humanidade para com sua efetivação.

Os direitos humanos, como um dos principais frutos da modernidade, foi fortemente atingido quando todas as teorias modernas de progresso, técnica e ciência romperam-se, com a realidade imposta pelo totalitarismo. Houve certa dificuldade de ressignificar os direitos humanos no mundo pós-segunda guerra e Hannah Arendt se propôs a essa tarefa, de modo a reconectar os significados políticos clássicos e contemporâneos.

Arendt também buscou compreender como o totalitarismo tornou-se possível sob diversos aspectos, e relata historicamente as peculiaridades de seu desenvolvimento. A autora consegue demonstrar a lógica absurda utilizada por Hitler no convencimento das massas, de que eles faziam parte de um momento grandioso, histórico, no qual certas decisões, mesmo que desumanas, precisavam ser tomadas.

Primeiramente Arendt apresenta as origens do anti-semitismo, e como ele foi utilizado pelo nazismo já que estava bastante disseminado na Europa. Os judeus foram tornados os "inimigos eleitos", à medida em que a propaganda com discurso de ódio os transformou em uma espécie de inimigo objetivo. Uma das características dos governos totalitários à época era essa criação de um “inimigo objetivo". Na Alemanha de Hitler foram os judeus, e na Rússia de Stálin os antigos aristocratas.

A autora consegue demonstrar todo o processo de desumanização utilizado pelos nazistas, por meio da propaganda, da burocracia, a desnaturalização e expatriação dos povos. No ápice do pensamento moderno surge uma maneira de extermínio em massa com o auxílio do modo burocrático.

Em seu capítulo, “O Declínio do Estado-Nação e o Fim dos Direitos do Homem", na obra "Origens do Totalitarismo", Arendt aborda a problemática dos Estados-Nação e sua homogeneidade, a crise pela qual a Europa passava após a Primeira Guerra Mundial, e toda a falácia em torno dos Direitos do Homem, tão anunciados após a Revolução Francesa. A autora demonstra o quanto o Estado moderno falhou. Atingiu a maioridade, apropriou-se da técnica, e ainda sim gerou um precedente aterrorizante: o holocausto, que ainda é um grande peso sobre a humanidade. 
Além de suas reflexões sobre a falência do Estado-Nação que é o modelo do Estado-moderno, Arendt também reflete sobre os direitos humanos e os motivos de seu fracasso quando mais se precisava deles. E é sob esta perspectiva que o presente trabalho procura refletir. O repensar de Arendt sobre os direitos humanos apresenta um entendimento crítico das teorias dos direitos humanos, e também uma interpretação apurada da autora da possibilidade de uma conduta adequada diante da problemática dos referidos direitos e a perspectiva de Arendt sobre as possibilidades de os direitos humanos serem efetivos dentro e fora das comunidades e dos Estados.

\section{A CRISE E A INSTABILIDADE POLÍTICA}

A primeira Guerra Mundial dilacerou irremediavelmente a comunidade europeia, como nenhuma outra guerra havia feito antes. A crise econômica gerou inflação, o que prejudicou muito os pequenos proprietários, sendo que inúmeros faliram. Apesar da Europa já ter passado por outras crises, essa abalou radicalmente as estruturas econômicas de seus países.

Assim, devido ao desgaste econômico houve a migração de grupos de pessoas que não eram considerados bem-vindos e não podiam ser assimilados em parte alguma. (ARENDT, 1989, p. 300). Um fenômeno talvez inédito e que serviu de combustível ao estabelecimento do totalitarismo, foi o ódio que repercutia entre os cidadãos da Europa. Algo que agravava a situação de migrantes com dificuldades econômicas.

O ódio, que certamente não faltara ao mundo, antes da guerra começou a desempenhar um papel central nos negócios públicos de todos os países, de modo que o cenário político, nos anos enganadoramente calmos da década de 20, assumiu uma atmosfera sórdida e estranha de briga em família à Strindberg. Nada talvez ilustre melhor a desintegração geral da vida política do que esse ódio universal vago e difuso de todos e de tudo, sem um foco que lhe atraísse a atenção apaixonada, sem ninguém que pudesse ser responsabilizado pelo estado de coisas - nem governo, nem burguesia, nem potência estrangeira. Partia, consequentemente, em todas as direções, cega e imprevisivelmente, incapaz de assumir um ar de indiferença sadia em relação a coisa alguma sob o sol. (ARENDT, 1989, p. 301).
A Europa passava por momentos difíceis, mas como ressalta Arendt, os países que perderam a guerra estavam em uma situação pior, além dos embargos sofridos havia ainda os Estados recém-estabelecidos com o fim da Monarquia Dual. Estes Estados tinham uma instabilidade maior para administrar.

Os últimos restos de solidariedade entre as nacionalidades não emancipadas do "cinturão de populações mistas" evaporaram-se com o desaparecimento de uma despótica burocracia central, que também havia servido para centralizar e desviar uns dos outros os ódios difusos e as reivindicações nacionais em conflito. Agora todos estavam contra todos, e, mais ainda, contra os seus vizinhos mais próximos - os eslovacos contra os tchecos, os croatas contra os sérvios, os ucranianos contra os formadores de Estados, ou entre minorias e maiorias: os eslovacos não apenas sabotavam constantemente o governo democrático de Praga como, ao mesmo tempo, perseguiam a minoria húngara em seu próprio solo, enquanto semelhante hostilidade contra o "povo estatal", por um lado, e entre si mesmas, por outro, animava as minorias insatisfeitas da Polônia. (ARENDT, 1989, p. 301).

A Rússia e a Áustria-Hungria estavam em situação crítica, mais vulneráveis que os outros países, acabaram por ser mais prejudicadas no intervalo do entre guerras. Tais Estados estavam em pior situação, e como suscita Arendt: "haviam perdido aqueles direitos que até então eram tidos e até definidos como inalienáveis, ou seja, os Direitos do Homem. " (ARENDT, 1989, p. 301).

A instabilidade política e a crise econômica facilitaram a propagação das ideologias de terror entre as massas, ideias absurdas foram facilmente propagadas entre a população. Algumas etnias como os judeus eram frequentemente alvos de ataque, isso muito antes do holocausto fazer qualquer sentido.

\section{OS INDESEJÁVEIS}

Com a crise se alastrando pela Europa, sentimentos nacionais vieram à tona junto ao ódio de todos contra tudo. Se a situação estava difícil para os nacionais, para os migrantes estava insustentável, eles eram considerados os indesejáveis da Europa. Arendt mostra como os migrantes "chamados de indesejáveis tornavam-se de fato os indésirables da Europa." (ARENDT, 1989, p. 302). Para se livrarem 
do problema, dos indesejáveis, surgiu na Europa um meio muito eficaz, a desnacionalização, meio burocrático de descartar pessoas, e tirá-las do âmbito de proteção dos direitos, até mesmo aqueles, uma vez ditos inalienáveis.

\begin{abstract}
A desnacionalização tornou-se uma poderosa arma da política totalitária, e a incapacidade constitucional dos Estados-nações europeus de proteger os direitos humanos dos que haviam perdido os seus direitos nacionais permitiu aos governos opressores impor a sua escala de valores até mesmo sobre os países oponentes. (ARENDT, 1989, p. 302).
\end{abstract}

Os direitos humanos em sua origem, eram no fundo uma concepção para toda a humanidade, tão sofrida por séculos de opressões, mas em certa medida o discurso dos direitos humanos não atingiu os que mais precisaram, e sob esta perspectiva é que se compreende a necessidade de repensar o modo como os direitos humanos são aplicados. A época do entre-guerras foi um período de total descaso para com estes direitos. "A própria expressão "direitos humanos" tornou-se para todos os interessados - vítimas, opressores e espectadores - uma prova de idealismo fútil ou de tonta e leviana hipocrisia." (ARENDT, 1989, p. 302).

Os indesejáveis não tinham acesso aos direitos humanos de modo que a promessa dos direitos humanos não era levada a sério. A inexequibilidade é decorrente da crise do pensamento, mas também consequência da ruptura, que não permitia o sentido das conexões morais feitas com o passado.

\section{OS POVOS SEM ESTADO}

Após os indesejáveis passarem pelo processo de expatriação, eles tornavam-se refugiados e apátridas, que não possuíam proteção legal de qualquer Estado, mesmo os em que residiam, ou de origem.

Não eram tempos tranquilos para os povos que não tinham nacionalidade dos Estados já constituídos, e essas pessoas eram tratadas como uma espécie de sub-cidadãos, para que os Estados-nação tomassem providências mais drásticas na tentativa de tornar a população dos Estados mais homogenia. "A expressão 'povos sem Estado' pelo menos reconhecia o fato de que essas pessoas haviam perdido a proteção do seu governo e tinham necessidade de acordos internacionais que salvaguardassem a sua condição legal."
(ARENDT, 1989, p. 313). Os povos sem Estado tinham dificuldades em recorrer a qualquer legislação que pudesse protegê-los, e desta forma tornaram-se o refugo da terra.

$\mathrm{Na}$ tentativa de solucionar a instabilidade gerada pelos povos sem Estado, criaram-se tratados internacionais afim propiciar alguma legislação em que estes povos pudessem se respaldar. Se a situação se complicava em toda a Europa, nos Estados já consolidados era muito pior para os povos que se constituíam apenas através de Tratados. Arendt explica o quanto os Tratados de Paz agravaram a situação dos povos sem Estado, algo que já era sensível pelas questões dos Estados-nações em formação.

As modernas condições do poder, que, exceto para os Estados gigantes, transformam a soberania nacional em pilhéria, junto com o advento do imperialismo e dos movimentos de unificação étnica, foram fatores externos que solaparam a estabilidade do sistema europeu de Estados-nações. Nenhum deles adviera diretamente da tradição e das instituições dos próprios Estados-nações. Sua desintegração interna só começou após a Primeira Guerra Mundial, em consequência do surgimento das minorias criadas pelos Tratados de Paz, e do movimento crescente de refugiados, resultados de revoluções. (ARENDT, 1989, p. 303).

A lógica dos Tratados não funcionava, o que era bastante óbvio sob o aspecto de que haviam muitas etnias na Europa oriental, o que impossibilitava as restrições exigidas para a formação de um Estadonação uninacional, intencionalmente homogêneo. Os Tratados aglutinaram vários povos num só Estado, gerando diversas tensões. O que os Tratados previam e o que era a realidade dos povos não guardava coincidência, gerando angústia e revolta entre as comunidades.

[...]regulamentos especiais, impostos de fora, para uma parte de sua população. Como resultado, os povos não agraciados com Estados, fossem "minorias nacionais" ou "nacionalidades", consideraram os Tratados um jogo arbitrário que dava poder a uns, colocando em servidão os outros. Os Estados recém-criados, por sua vez, que haviam recebido a independência com a promessa de plena soberania nacional, acatada em igualdade de condições com as nações ocidentais, olhavam os Tratados de minorias como óbvia quebra de promessa, e como prova de discriminação, uma vez que somente os novos Estados, e nem mesmo a Alemanha derrotada [com 
exceção do território da Silésia oriental, dividida em 1920 com a Polônia em decorrência de plebiscito], ficavam subordinados a eles. (ARENDT, 1989, p. 304).

Após a dissolução da Monarquia Dual, havia a necessidade de algum tipo de organização daqueles povos, porém a Europa já tinha problemas demais, e acabou não dando conta de assimilar os Estados recentes, escolheu ignorar os diversos povos sem Estado, ao invés de permitir a autodeterminação dos povos e o fortalecimento das comunidades.

O desconcertante vácuo de poder deixado pela dissolução da Monarquia Dual... continuar ignorando mais de 100 milhões de europeus que nunca haviam atingido o estágio de liberdade nacional... "povos sem história"... Como o objetivo de todos era preservar o status quo europeu, a concessão do direito à autodeterminação nacional e à soberania a todos os povos europeus parecia realmente inevitável: a alternativa seria condená-los impiedosamente à posição de povos coloniais (coisa que os movimentos de unificação étnica sempre propuseram), introduzindo assim métodos coloniais na convivência europeia. (ARENDT, 1989, p. 304).

A intensão de manter a Europa caminhando sem mais problemas, não funcionou. O status quo europeu não podia ser mantido. "Só após a queda dos últimos remanescentes da autocracia europeia ficou claro que a Europa havia sido governada por um sistema que nunca levou em conta as necessidades de pelo menos $25 \%$ da sua população. " E a dissolução das monarquias, e os Estados sucessores não conseguiram superar este problema, "cerca de $30 \%$ dos seus quase 100 milhões de habitantes eram oficialmente minorias." Os povos nacionalmente frustrados constituíam 50\% da população total. (ARENDT, 1989, p. 305).

Tal situação fazia com que fosse natural às nacionalidades não respeitarem e serem desleais com o governo que lhes fora imposto, afinal suas nacionalidades eram reprimidas do modo mais eficiente possível. O que Arendt vem alertar em seus escritos é que a população nacionalmente frustrada acreditava que as coisas só mudariam, e que a única saída seria a emancipação nacional, e que apenas deste modo atingiriam a verdadeira liberdade. Era visto como normal que povos sem um Estado-nacional fossem privados dos direitos humanos.
A ideia de Estado, apesar das alterações trazidas pela globalização, ainda é forte nos dias de hoje e causa ainda muitas injustiças pelo mundo, sendo que a concepção de Direitos ainda é muito vinculada ao Estado. A manutenção de direitos fora de um Estado sempre é algo difícil, muito embora hoje seja possível contar com sistemas (Universal e Regionais) de proteção aos direitos humanos. Em seu livro Origens do Totalitarismo Arendt faz uma crítica a este modo de se pensar os direitos humanos. E a respeito da criação do Estado de Israel, Arendt afirma que a criação do Estado de Israel segue essa lógica de que para se ter direitos, há a necessidade de ter cidadania, e de que a emancipação nacional só se dá por meio da criação de um Estado-nacional. Mas tal lógica acaba por gerar mais violência visto que sempre haverá grupos sem Estado.

A autodeterminação dos povos é fundamental, hoje existem Estados que são plurinacionais ( v.g.Bolívia e Equador) e a ideia de criar Estados com um só povo, uma só nação, acaba por gerar a repressão da pluralidade cultural presente em algumas comunidades.

A convicção de que apenas a criação de um Estado daria um jeito no sofrimento de cada povo, surgiu na Revolução Francesa, onde os Direitos do Homem eram ligados a soberania nacional.

Essa convicção, baseada no conceito da Revolução Francesa que conjugou os Direitos do Homem com a soberania nacional, era reforçada pelos próprios Tratados de Minorias, os quais não confiavam aos respectivos governos a proteção das diferentes nacionalidades do país, mas entregavam à Liga das Nações a salvaguarda dos direitos daqueles que, por motivos de negociações territoriais, haviam ficado sem Estados nacionais próprios, ou deles separados, quando existiam. (ARENDT, 1989, p. 305).

Os Tratados foram a opção dos povos sem Estado, supostamente um método de assimilação, mas que não tinham eficácia à época. E os representantes das grandes nações sabiam que as minorias que existem num Estado-nação deviam mais cedo ou mais tarde, ser assimiladas ou liquidadas. (ARENDT, 1989, p. 306). A constante tensão entre os Estados e as minorias não previam uma saída pacífica. De certa forma os métodos utilizados pelos regimes totalitários, tanto os expurgos quanto a expulsão dos judeus e até mesmo os campos de concentração, eram uma saída 
provável dentro da lógica totalitária e dentro da lógica do Estado-nação.

Para discutir a situação dos $30 \%$ da população da Europa eram realizados os Congressos de minorias, onde preferia-se discutir os interesses nacionais de cada minoria, do que o interesse comum entre todas elas. Arendt demonstra a desunião dessas minorias que faziam parte dos congressos. Assim que os judeus começaram a perder direitos no regime nazista, e tentaram ajuda no Congresso, não tiveram êxito. Os demais grupos considerados minoritários preferiram apoiar o anti-semitismo.

A harmoniosa relação entre os judeus e os alemães - até o advento de Hitler - mantinha o congresso coeso. Mas, quando em 1933 a delegação judaica exigiu um protesto contra o tratamento dos judeus no Terceiro Reich (moção que, a rigor, não tinha o direito de fazer, pois os judeus alemães não eram considerados e não constituíam uma minoria), os alemães nacionalmente minoritários anunciaram sua solidariedade com a Alemanha, já nazista, e conseguiram o apoio da maioria das delegações dos grupos minoritários, que abraçaram o anti-semitismo, florescente em todos os Estados sucessórios. $\mathrm{O}$ Congresso, abandonado para sempre pela delegação judaica, mergulhou desde então em completa insignificância. (ARENDT, 1989, p. 308).

As minorias sempre existiram, mas o que os Tratados e os Estados fizeram foi transformar tais minorias em instituição permanente e fazer com que algumas pessoas ficassem fora da gama de direitos. Assim começaram a tratar direitos como privilégios somente dos nacionais, sem dar qualquer chance de empoderamento para estas outras comunidades.

A cidadania introduziu um novo tipo de privilégio que era protegido por alguns ao excluir outros. Após as revoluções, os Estados-nações são definidos por fronteiras territoriais, que os separam de outros Estados e excluem outros povos e nações. A cidadania passou a exclusão de classe para exclusão de nação, que se tornou uma barreira de classe disfarçada. (DOUZINAS, 2009, p. 116).

Essas minorias não condiziam com seu nome, tornavam-se em milhões de pessoas vivendo fora da proteção legal e sem perspectiva de mudança.

Inédito para a história era que os Tratados formalizassem o descaso com que eram tratadas as minorias, "os tratados das Minorias diziam em linguagem clara aquilo que até então era apenas implícito no sistema operante dos Estados-nações". (ARENDT, 1989, p. 308). Na lógica dos Estados-nações, apenas os nacionais são sujeitos de direito e podem exercer sua cidadania, apenas pessoas da mesma origem nacional poderiam gozar de proteção legal por parte do Estado. Para os indivíduos de nacionalidade diferente era necessária alguma lei de exceção "até que, ou a não ser que, estivessem completamente assimilados e divorciados de sua origem. " (ARENDT, 1989, p. 308). Para as demais populações era tido como normal que tais pessoas não tivessem os mesmos direitos, afinal elas "insistiam" em uma nacionalidade diferente. Tal equívoco legitimava cada vez mais arbitrariedades realizadas por parte do Estado contra tal população.

Tais ocorrências relacionadas aos Tratados e aos povos sem Estado eram previstas, a estrutura do Estado-nação é sem dúvida excludente. Arendt aponta que como o surgimento dos Estados-nação coincidia muitas vezes com governos constitucionais, acabavam por ter o monopólio da representação legal, mas ao mesmo tempo contavam com um frágil equilíbrio que acabara levando a sua desintegração.

De modo que, ao se romper o precário equilíbrio entre a nação e o Estado, entre o interesse nacional e as instituições legais, ocorreu com espantosa rapidez a desintegração dessa forma de governo e de organização espontânea de povos. E a desintegração, por mais curioso que pareça, começou precisamente no momento em que o direito à autodeterminação era reconhecido em toda a Europa, e quando a convicção fundamental da supremacia da nação sobre todas as instituições legais e "abstratas" do Estado tornava-se universalmente aceita. (ARENDT, 1989, p. 309).

A autodeterminação dos povos seria uma alternativa para os povos sem Estado. Os Estados não podem levar até as últimas consequências o ideal de homogeneidade. Como já visto, isto vai totalmente contra a condição humana da pluralidade, e também contra os direitos humanos.

\section{OS APÁTRIDAS}

Em favor dos Tratados de minoria se dizia que os Estados mais antigos e mais fortes como a França (nation par excellence), não precisavam de leis complementares, posto que sua própria Constituição era 
fundamentada nos Direitos do Homem, portanto, as diferentes populações que ali vivessem não precisariam de leis específicas. Já os Estados sucessórios precisavam da excepcional invocação temporária dos direitos humanos. Mas tal discurso se demonstrou falso, quando surgiram os povos sem Estado que não tinham a quem recorrer por direitos humanos.

Anteriormente as deportações em massa, as minorias eram povos sem Estado parcialmente, precisavam sim de proteção adicional, através dos Tratados, mas pertenciam de certo modo a algum corpo político. Tinham seus direitos de preservação da própria cultura ameaçados, mas tinham alguns direitos preservados, como Arendt comenta: viver, residir, trabalhar. $\mathrm{O}$ problema maior surge quando se iniciaram as transferências maciças de população, na qual as pessoas tornavam-se indeportáveis, e nenhum país manifestava desejo nem interesse em acolhê-las.

Para Arendt, muito mais catastróficas as consequências eram para os apátridas, "que é o mais recente fenômeno de massas da história contemporânea, e a existência de um novo grupo humano, em contínuo crescimento, constituído de pessoas sem Estado, grupo sintomático do mundo após a Segunda Guerra Mundial. " (ARENDT, 1989, p. 310). Os apátridas não possuíam qualquer nacionalidade reconhecida, não podendo assim contar com a proteção de algum Estado. Mas após a Primeira Guerra Mundial, na contramão disso, algumas pessoas se refugiavam na situação de apátrida para que não fossem deportadas, devido a sua nacionalidade.

Desprovido de importância, aparentemente apenas uma anomalia legal, o apatride recebeu atenção e consideração tardias quando, após a Segunda guerra Mundial, sua posição legal foi aplicada também aos refugiados que, expulsos de seus países pela revolução social, eram desnacionalizados pelos governos vitoriosos. (ARENDT, 1989, p. 311).

Arendt conta que tais condutas por parte dos Estados podem parecer normais diante de uma guerra, mas o que realmente ocorreu: é que na época, as desnacionalizações eram realizadas com naturalidade, demonstrando toda a intolerância presente na Europa. Os governos mesmo não sendo totalitários, já executavam tais medidas, adotando características de regimes totalitários.
O pior é que o número de pessoas que são apátridas em potencial continua a aumentar. Antes da última guerra, somente os países totalitários ou as ditaduras semitotalitárias recorriam à arma da desnaturalização contra pessoas que eram cidadãos por nascimento; mas chegou-se ao ponto em que até as democracias livres, como, por exemplo, os Estados Unidos, pensaram seriamente em privar da cidadania os americanos natos que fossem comunistas. (ARENDT, 1989, p. 313).

Transformar um cidadão em apátrida é privá-lo do mundo comum, restringindo-lhe a vida privada. É afastá-lo da possibilidade da ação e do discurso, retirando-lhe a sensação de pertencimento de qualquer comunidade. A expatriação foi uma importante arma utilizada pelos regimes totalitários, mas sua gravidade aumenta quando até países democráticos pensam em utilizar este procedimento para punir cidadãos. Tal precedente vai totalmente contra a proposta de Arendt para os direitos humanos.

\section{OS DIREITOS DO HOMEM}

A Revolução Francesa foi um marco importante na construção dos ideais políticos ocidentais, e embora tenha avançado no rumo a concretização de direitos, deve-se analisar os acontecimentos de modo cético e não apaixonado, para fazer uma reflexão que repense os não acertos da Revolução e seus desdobramentos também sobre a política atual.

Hannah Arendt debruçou-se sobre os teóricos da Revolução Francesa em sua obra "On Revolution", realizando assim uma importante reflexão para o âmbito dos estudos políticos. Em "Sobre a Revolução" Arendt demonstra as influências da Revolução Francesa nas Revoluções decorrentes, e a interferência do social nas questões políticas. Mas também menciona o fato de a Declaração de Direitos do Homem e do Cidadão (1789) não ser algo direcionado a todos, na verdade, naquele momento na França era claro que aqueles direitos eram apenas para alguns homens, os verdadeiros e concretos destinatários daqueles direitos eram, sem dúvida, o homem branco e proprietário. Portanto até mesmo uma das raízes dos direitos humanos já apresenta uma concepção excludente e elitista.

Mesmo que a Declaração de Direitos do Homem e do Cidadão tenha sido elaborada com intensões puras, não era o que bastava para que os direitos básicos 
de toda a humanidade fossem respeitados. E mesmo que muitas pessoas continuassem lutando para que direitos fossem verdadeiramente inalienáveis, a realidade as contradizia, existiam em todos os lugares pessoas sem direito algum.

Nenhum paradoxo da política contemporânea é tão dolorosamente irônico como a discrepância entre esforços idealistas bem-intencionados, que persistiam teimosamente em considerar "inalienáveis" os direitos desfrutados pelos cidadãos dos países civilizados, e a situação de seres humanos sem direito algum. Essa situação deteriorou-se, até que o campo de internamento - que, antes da Segunda Guerra Mundial, era exceção e não regra para os grupos apátridas - tornou-se uma solução de rotina para o problema domiciliar dos "deslocados de guerra". (ARENDT, 1989, p. 312).

Devido ao grande número de migrações forçadas, algo que era um marco para os Direitos do Homem, como a concessão de asilo, teve abolição tácita pelos Estados-nações. Arendt explica a importância que o asilo tinha não só para os refugiados, mas para as relações internacionais.

Sua longa e sagrada história data do começo da vida política organizada. Desde os tempos antigos, com esse direito protegeu-se o refugiado - e a área que o acolhia - contra situações que o forçassem a colocar-se fora da lei por circunstâncias alheias ao seu controle. Assim, o asilo era o único remanescente moderno do princípio de que quid est in território est de território, pois em todos os outros casos o Estado moderno tendia a proteger os seus cidadãos além de suas fronteiras para que, graças a tratados recíprocos, permanecessem sujeitos às leis do seu país, mesmo morando fora dele. Mas, embora o direito de asilo continuasse a funcionar num modo organizado em estados-nações e em certos casos, tenha até sobrevivido às duas guerras mundiais, tornou-se paulatinamente anacrônico, entrando até em conflito com os direitos internacionais do Estado. Assim, não se encontra esse direito na lei escrita, em nenhuma constituição ou acordo internacional, e o Pacto da Liga das Nações nem ao menos o menciona. A esse respeito, tem o mesmo destino a Declaração dos Direitos do Homem, que também nunca em lugar nenhum foi transformada em lei, levando uma existência mais ou menos irreal, como recurso em certos casos excepcionais em que as instituições legais normais não eram suficientes. (ARENDT, 1989, p. 314).
A nacionalidade era vista como algo muito importante para todos os povos, e os sem Estado mantinham firme o apego às suas origens, algo que dificultava a assimilação por qualquer outra comunidade nacional. A surpreendente teimosia em reter sua nacionalidade, evitava a sua assimilação, pois eles nem sequer se agrupavam a outras comunidades, como as minorias haviam feito temporariamente, para defender interesses comuns. (ARENDT, 1989, p. 316).

Conclui-se que a Declaração dos Direitos do Homem mesmo apresentando um tom universalista, jamais alcançou tal propósito. Douzinas também aponta para a fragilidade de tal documento:

Podemos concluir que o "homem" das declarações é uma abstração, universal, mas irreal, uma entidade "desencarregada" despojada de suas características. Como representante da Razão, ele não tem tempo nem lugar. O cidadão, por outro lado, é sempre um "homem inglês" burkeano. Tem direitos e deveres conferidos a ele por leis do Estado e pela tradição nacional; deve ficar subordinado à lei para tornar-se sujeito da lei. Conforme sugere Jay Bernstein, "a cidadania situa-se entre e medeia a particularidade abstrata da identidade pessoal e a universalidade abstrata dos direitos humanos. Os indivíduos somente têm direitos na comunidade". Para os que não têm representação, sobra muito pouco. Os sem-Estado, os refugiados, as minorias de vários tipos não têm quaisquer direitos humanos. (DOUZINAS, 2009, p. 119).

O homem abstrato da Declaração não auxiliava na proteção de homens que escapassem ao padrão europeu, não proporcionando a universalidade prescrita na carta da Revolução Francesa. Os homens reais, os que mais precisavam da proteção dos direitos do homem, não se sentiam e nem foram contemplados, a universalidade pretendida pela Declaração não ocorreu.

\section{OS APÁTRIDAS E A POLÍCIA, A NEGAÇÃO DOS DIREITOS DO HOMEM}

Os "povos sem Estado" facilmente se transformaram em refugiados e apátridas e estavam infiltrados nos países da Europa ocidental. O jeito mais fácil que esses Estados encontraram para livrarem-se destas pessoas indésirables, era deixá-los à mercê da polícia que tinha total poder para agir como bem quisessem. 
A possibilidade de naturalização era restrita a casos excepcionais, de modo que não funcionava para o caso dos refugiados e apátridas. Mesmo olhando apenas pelo viés administrativo, nenhum país da Europa estava preparado para realizar naturalização em massa. Tornou-se um grande problema a ser resolvido, pois milhares de pessoas estavam nessa situação. Os governos europeus nunca haviam lidado com um problema de tamanha magnitude, sentiram-se simplesmente impotentes, e a condição de apátrida transformou-se em um perigo para suas instituições legais e políticas.

Os apátridas não contavam com direitos básicos, como os de moradia e trabalho, o que muitas vezes os levavam a transgredir as leis. Arendt retrata que a ilegalidade dos apátridas só cessava quando estes cometiam crimes comuns, porque dessa maneira eles se enquadravam às leis vigentes, o que fazia com que fossem tratados como os cidadãos. Algo que demonstra a triste realidade dessas pessoas, que apenas como transgressores da lei, poderiam ser protegidos por elas.

A melhor forma de determinar se uma pessoa foi expulsa do âmbito da lei é perguntar se, para ela, seria melhor cometer um crime. Se um pequeno furto pode melhorar a sua posição legal, pelo menos temporariamente, podemos estar certos de que foi destituída dos direitos humanos. Pois o crime passa a ser então, a melhor forma de recuperação de certa igualdade humana, mesmo que ela seja reconhecida como exceção à norma. (ARENDT, 1989, p. 320).

A questão dos apátridas não demorou para que se tornasse um caso de polícia. As polícias foram incumbidas de resolver qualquer problema relacionado aos povos sem Estado. O que os Estados não puderam resolver era resolvido pela polícia, que recorria ao uso da força. Não se podia prever o quanto isso influenciaria no decorrer dos acontecimentos, como comenta Arendt, a partir deste fato a polícia ganhou projeção em sua importância dentro dos assuntos públicos.

O Estado-nação, incapaz de prover uma lei para aqueles que haviam perdido a proteção de um governo nacional, transferiu o problema para a polícia. Foi essa a primeira vez em que a polícia da Europa ocidental recebeu autoridade para agir por conta própria, para governar diretamente as pessoas; nessa esfera da vida pública, já não era um instrumento para executar e fazer cumprir a lei, mas se havia tornado autoridade governante independente de governos e de ministérios. (ARENDT, 1989, p. 321).

A reflexão aqui necessária é de o quanto a polícia foi utilizada para resolver uma questão que não lhe competia e para a qual seus meios não eram os mais adequados, já que os refugiados e apátridas não eram criminosos, na verdade seu problema era muito maior, e estavam sim em embate com a própria ideologia do Estado-nação e sua unidade intrínseca.

Desta forma a polícia galgou um certo status até se tornar o que poderia ser chamado de braço da burocracia. Mas antes disso, ela já estava adquirindo poder, mesmo fora do âmbito da lei. Arendt conta como se deu a consolidação do poder da polícia, que estava sendo adquirido por meio do domínio de grandes grupos de pessoas. Um exemplo é o da Alemanha nazista, onde a polícia podia expedir decretos nos quais decidia-se quem era cidadão e quem não era. As pessoas perdiam suas nacionalidades por meio do trabalho da própria polícia.

Na Alemanha nazista, as leis de Nuremberg, com a sua distinção entre os cidadãos do Reich (Reichsbürguer - cidadãos completos) e nacionais (Volsbürguer - cidadãos de segunda classe sem direitos políticos), haviam aberto o caminho para um estágio final no qual os "nacionais" de "sangue estrangeiro" podiam perder a nacionalidade por decretos; só a deflagração da guerra evitou a promulgação de uma legislação nesse sentido, que havia sido detalhadamente preparada.

\section{$[\ldots]$}

O fato de que os alemães encontraram tão pouca resistência por parte das polícias dos países que haviam ocupado, e de que os alemães puderam organizar o terror com a ajuda dos policiais locais, foi em parte devido à poderosa posição que a polícia havia conquistado no decorrer dos anos em seu irrestrito e arbitrário domínio sobre os apátridas e os refugiados. (ARENDT, 1989, p. 321/322).

Tais decretos segregavam a população, como se aqueles que o Estado decidiu não mais tratar como cidadão, tivesse algum tipo de vírus mortal o qual deveria ser exterminado. Aos poucos todos os seus direitos foram retirados, e quando só lhe restou a vida, o Estado também encontrou uma solução, final.

Os apátridas minorité par excellence eram um problema, e a maioria dos Estados não soube lidar com esta questão, mas foi na Alemanha de Hitler, que 
aparentemente surgiu uma solução para a questão dos apátridas, uma das piores soluções já inventadas por qualquer Estado. O extermínio em massa.

\begin{abstract}
Mas, nos anos que se seguiram à bem-sucedida perseguição de Hitler aos judeus, todos os países com minorias começaram a pensar em se desfazer de algum modo de seus grupos minoritários, e era natural que começassem a realizar essas ideias a partir da minorité par excellance, a única nacionalidade que realmente não tinha qualquer outra proteção além de um sistema de minorias que, a essa altura, não era mais que zombaria. [...]

Nenhum dos estadistas se apercebia de que a solução de Hitler para o problema judaico - primeiro, reduzir os judeus alemães a uma minoria não reconhecida na Alemanha; depois, expulsá-los como apátridas; e, finalmente, reagrupa-los em todos os lugares em que passassem a residir para enviá-los aos campos de extermínio - era uma eloquente demonstração para o resto do mundo de como realmente "liquidar" todos os problemas relativos às minorias e apátridas. (ARENDT, 1989, p. 323).
\end{abstract}

As pessoas despojadas de seus direitos, não encontrando qualquer tipo de proteção internacional, acabaram mortas em campos de concentração, contrariando qualquer ideal de direitos humanos.

\section{OS DIREITOS HUMANOS}

Diante do quadro de desnacionalizações, deportações em massa, pessoas sem qualquer proteção legal, é inevitável que se recorra aos direitos humanos que surgiram justamente com o propósito de fornecer a proteção para humanos, independente da estrutura do Estado. Direitos mínimos que protegeriam a dignidade de cada ser humano. Mas toda a construção teórica em torno dos direitos humanos foi irrelevante no caso dos refugiados e apátridas, neste período. $\mathrm{E}$ Arendt se depara com uma luta inglória, a argumentação dos direitos humanos diante da superestrutura dos Estados-nação e da soberania dos Estados.

A questão dos apátridas deixou muito claro, que os indivíduos não nascem iguais, a população apátrida era enjeitada e explicitamente exposta como "sem direitos", "até que uma investigação de suas características raciais pudesse ser feita". De modo a inverter, "o princípio de que todo indivíduo nasce com direitos inalienáveis garantidos por sua nacionalidade, agora todo indivíduo nasce sem direitos, a não ser que mais tarde se possa determinar o contrário." (ARENDT, 1989, p. 221).

Arendt aborda sobre o fracasso da ajuda humanitária dada aos apátridas e refugiados, que foram basicamente nenhuma, como as perplexidades dos direitos do homem. A Declaração dos Direitos do Homem, marco histórico, no fim do século XVIII, se apresentou como uma esperança aos mais desfavorecidos, como se a partir daquele momento qualquer homem pudesse reclamar seus direitos ao Estado. Principalmente significava que o próprio homem seria a fonte da Lei, e não Deus ou os costumes da história. Que ele estaria livre de qualquer espécie de tutela, e prenunciava que ele havia atingido a maioridade. (ARENDT, 1989, p. 324).

A Declaração dos Direitos do Homem destinava-se também a ser uma proteção muito necessária tendo em vista que os indivíduos já não estavam a salvo nem nos Estados em que haviam nascido. Os Direitos do Homem haviam sido definidos como "inalienáveis" justamente porque se supunha serem independentes de todos os governos, mas o que sucedia é que no momento em que seres humanos deixavam de ter um governo próprio, não restava nenhuma autoridade para protegê-los e nenhuma instituição disposta a garanti-los. (ARENDT, 1989, p. 325). Ou seja, só existiam direitos para os indivíduos que eram cidadãos de algum Estado.

Arendt aponta para o fato de que os protetores dos Direitos do Homem, não possuíam a força necessária para enfrentar os Estados, nem para ressignificar os direitos humanos. Suas tentativas sempre eram vistas como vãs, não tinham credibilidade nem com as pessoas que precisavam de ajuda.

O pior é que as sociedades formadas para a proteção dos Direitos do Homem e as tentativas de chegar a uma nova definição dos direitos humanos eram patrocinadas por figuras marginais - por alguns poucos juristas internacionais sem experiência política, ou por filantropos apoiados pelos incertos sentimentos de idealistas profissionais. Os grupos que formavam e as declarações que faziam tinham uma estranha semelhança de linguagem e composição com os das sociedades protetoras dos animais. Nenhum estadista, nenhuma figura de certa importância podia leva-los a sério; e nenhum dos partidos liberais ou radicais da Europa achava necessário incorporar aos seus programas uma nova declaração dos direitos 
humanos. Nem sequer as próprias vítimas, em suas numerosas tentativas de escapar do labirinto de arame farpado no qual haviam sido atiradas pelos acontecimentos, invocaram - nem antes nem depois da Segunda Guerra Mundial - esses direitos fundamentais, que tão evidentemente lhes eram negados. Pelo contrário, as vítimas compartilhavam o desdém e a indiferença das autoridades constituídas em relação a qualquer tentativa das sociedades marginais de impor os direitos humanos em qualquer sentido elementar ou geral. (ARENDT, 1989, p. 326).

A fragilidade observada por Arendt em se tratando de defensores dos direitos humanos, ainda ocorre nos dias atuais. Os Direitos do Homem foram proclamados para proteger alguns indivíduos do poder do Estado e não todos, comumente ouvimos de que a Declaração de Direitos do Homem proclamada na revolução francesa teve efetividade apenas para homens, brancos, e proprietários de terras.

Os direitos humanos são comumente utilizados em discursos sem conexão com a realidade, o que aumenta a descrença em alguns esforços humanitários. O professor Marcelo Neves (NEVES, 2005, p. 20), realizou uma desconstrução da perspectiva dos direitos humanos para mostrar como estes direitos se apresentam na sociedade, e uma de suas facetas mais significativas ainda hoje é sem dúvida o discurso simbólico. A perda de significado não só nos discursos tornou-se evidente. Os Direitos do Homem, supostamente inalienáveis, mostravam-se, em boa parte das vezes, inexequíveis.

\section{OCUPAR UM LUGAR NO MUNDO}

Arendt relata que os apátridas e refugiados antes de perderem seus direitos, perderam seus lares. E o que era sem precedentes, não era a perda de seus lares, mas sim a impossibilidade de encontrar um novo lar.

De súbito revelou-se não existir lugar algum na terra aonde os emigrantes pudessem se dirigir sem as mais severas restrições, nenhum país ao qual pudessem ser assimilados, nenhum território em que pudessem fundar uma nova comunidade própria. Além do mais, isso quase nada tinha a ver com qualquer problema material de superpopulação, pois não era um problema de espaço ou de demografia. Era um problema de organização política. (ARENDT, 1989, p. 327).
E esquematicamente tais pessoas foram sendo destituídas de seus direitos. A segunda perda, além da desnacionalização, foi a de proteção de seus governos. Deste modo, durante a última guerra, "os apátridas estavam em posição invariavelmente pior que os estrangeiros inimigos, que ainda eram de certo modo protegidos por seus governos através de acordos internacionais." (ARENDT, 1989, p. 327).

Toda essa situação é um exemplo das muitas perplexidades inerentes a concepção dos direitos humanos. A construção teórica dos direitos humanos, ou pelo menos a que se tinha até a Segunda Guerra Mundial, figurava como um conceito abstrato e não filosoficamente constituído a ponto de corresponder a uma prática. Com uma simples reflexão é possível desconstruir a ideia comumente apresentada de direitos humanos, e demonstrar que os principais direitos podem ser retirados em diversas situações, mas não é exatamente isso que despoja os seres humanos dos seus direitos.

Não importa como tenham sido definidos no passado (o direito à vida, à liberdade e à procura da felicidade, de acordo com a fórmula americana; ou a igualdade perante a lei, a liberdade, a proteção da propriedade e a soberania nacional, segundo os franceses); não importa como se procure aperfeiçoar uma fórmula tão ambígua como a busca da felicidade, ou uma fórmula antiquada como o direito indiscutível à propriedade; a verdadeira situação daqueles a quem o século XX jogou fora do âmbito da lei mostra que esses são direitos cuja perda não leva à absoluta privação de direitos. O soldado durante a guerra é privado do seu direito à vida; o criminoso, do seu direito à liberdade; todos os cidadãos, numa emergência, do direito de buscarem a felicidade; mas ninguém dirá jamais que em qualquer desse caos houve uma perda de direitos humanos. Por outro lado, esses direitos podem ser concedidos (se não usufruídos) mesmo sob condições de fundamental privação de direitos. (ARENDT, 1989, p. 329).

Para Arendt não é a privação de direitos em si que fez da situação dos apátridas e dos refugiados tão grave, mas o pior e mais cruel foi o fato de que essas pessoas foram privadas de viver em comunidade. Elas não mais pertenciam a qualquer comunidade, e nenhuma lei foi feita para elas. (ARENDT, 1989, p. 329).

Sem qualquer lei destinada a estas pessoas, era como se não houvesse qualquer direito. Não havia um lugar no mundo em que elas pudessem existir em 
plenitude humana. O prolongamento de suas vidas era devido à caridade e não ao direito, pois não existia nenhuma lei que poderia forçar as nações a alimentá-las. Tornava-se cada dia mais lógico exterminar tais pessoas. A impossibilidade de um lugar, onde tais pessoas pudessem agir, e um espaço em que suas vozes fossem ouvidas, fez a maior diferença no fracasso dos direitos humanos. Arendt é categórica em afirmar que a privação dos direitos humanos está principalmente, na privação da condição humana por excelência.

A privação fundamental dos direitos humanos manifesta-se, primeiro e acima de tudo, na privação de um lugar no mundo que torne a opinião significativa e a ação eficaz. Algo mais fundamental do que a liberdade e a justiça, que são os direitos do cidadão, está em jogo quando deixa de ser natural que um homem pertença a comunidade em que nasceu, e quando o não pertencer a ela não é um ato da sua livre escolha, ou quando está numa situação em que, a não ser que cometa um crime, receberá um tratamento independente do que ele faça ou deixe de fazer. Esse extremo, e nada mais, é a situação dos que são privados dos seus direitos humanos. São privados não do seu direito à liberdade, mas do seu direito à ação; não do direito de pensarem o que quiserem, mas do direito de opinarem. Privilégios, (em alguns casos), injustiças (na maioria das vezes), bênçãos ou ruínas lhes serão dados ao sabor do acaso e sem qualquer relação com o que fazem, fizeram ou venham a fazer. (ARENDT, 1989, p. 330).

A ação, é vista por Arendt como a condição humana por excelência, o que mais nos diferencia dos animais. E é por esse motivo que a privação da ação é algo extremamente grave. Para Arendt retirar a possibilidade de ação de qualquer ser humano é atingir em cheio a sua humanidade intrínseca, é restringi-lo de sua própria humanidade, e condená-lo a mera vida biológica.

Portanto, o que se torna mais preocupante é que tal calamidade vem abatendo um número cada vez maior de pessoas. E não é a perda de direitos específicos, mas a perda de uma comunidade disposta e capaz de garantir quaisquer direitos, que viabilize os direitos humanos. "O homem pode perder todos os chamados Direitos do Homem sem perder sua qualidade essencial de homem, sua dignidade humana. Só a perda da própria comunidade é que o expulsa da humanidade." (ARENDT, 1989, p. 331).
E é neste ponto que se encontra o dilema dos direitos humanos, algo mais precisa acontecer para que os mesmos tenham efetividade. A reflexão de Arendt aponta para a necessidade de um compromisso de toda a humanidade, para a proteção mesma do indivíduo em qualquer lugar do planeta. Hoje se caminha para isso por meio da consolidação dos Sistemas Internacionais Protetivos, não obstante ainda falte muito para tal consolidação. Infelizmente se está ainda longe do reconhecimento de que todo e qualquer ser humano precisa ser respeitado como tal.

Quando Arendt fala em direito a ter direitos ela refere-se ao direito como ação, ou seja, uma política efetiva realiza conjuntamente pelas pessoas. Não bastando apenas a criação de leis, que seriam para Arendt elemento necessário, mas especialmente uma ação ligada ao artifício humano, a obra realizada pelos homens.

\section{CONCLUSÃO}

O totalitarismo concebido por Arendt como a ruptura da modernidade com a tradição, a drástica transformação do Estado moderno e suas novas possibilidades de destruição em massa, devem servir para que a humanidade se organize politicamente para um novo rumo. A Declaração Universal dos Direitos Humanos (1948) foi uma tentativa de proteção universal, porém não se afasta muito da Declaração Francesa, trazendo consigo a mesma descrença.

A Declaração Universal dos Direitos Humanos, adotada pela Assembleia Geral das Nações Unidas em 1948, seguiu de perto a Declaração Francesa, tanto em essência quanto em forma. Conforme observou um comentador contemporâneo, "os idealizadores da Declaração das Nações Unidas de 1948 seguiram o modelo estabelecido pela Declaração Francesa dos Direitos do Homem e do Cidadão, de 1789, embora substituíssem o 'homem' pelo mais ambíguo 'humano' ao longo de todo o texto". (DOUZINAS, 2009, p. 99).

Após a Segunda Guerra mundial e até os dias atuais existem reflexões necessárias a serem feitas a respeito dos direitos humanos. Arendt critica os direitos humanos e como eles foram concebidos até hoje. Sua ideia sobre os direitos humanos se apresenta como uma análise do que se observou em um momento extremo, a perda dos mesmos recaem em 
implicações perigosas para a humanidade como um todo. "O perigo é que uma civilização global, universalmente correlata, possa produzir bárbaros em seu próprio seio por forçar milhões de pessoas a condições que, despeito de todas as aparências, são as condições da selvageria." (ARENDT, 1989, p. 336).

A construção teórica em torno dos direitos humanos, abordava uma concepção de direitos que pudessem ser direcionados à todos os seres humanos, independentemente de suas diferenças sociais, físicas e políticas. Foi uma concepção do pensamento jusnaturalista de cunho racional moderno e foi um pensamento revolucionário principalmente contra os abusos dos Estados absolutistas. Estes direitos destinados a todos eram tidos como naturais, atribuídos aos homens por leis naturais e tidos como universais. Portanto não eram os homens que criavam tais leis, eles apenas as reconheciam. "As cartas de direitos que vão surgir a partir do final do século XVIII serão denominadas, significativamente, Declarações de Direitos. " (RIBAS, 2013, p.170). Ou seja, declaram algo preexistente.

Em seu livro Origens do Totalitarismo, Arendt consegue demonstrar como a Europa lidou com os problemas das minorias que surgiram devido a configuração dos Estados-nação, tal evento fez com que as pessoas só tivessem acesso a direitos na medida em que fossem cidadãos. "A ideia de nacionalidade que se evocava aí transpirava uma ideologia racial. Os não nacionais num território "estranho" eram vistos como anomalias, "exceções" num mundo de resto estável." (ARENDT, 1989, p. 301).

Num processo que Arendt chamou de "matar a pessoa jurídica do homem” (ARENDT, 1989, p.498), procedimento necessário para que os regimes totalitários alcançassem o "domínio total”, tal processo se inicia com a expulsão de certos indivíduos da proteção legal dada aos cidadãos. Quando algumas categorias de pessoas foram excluídas da proteção da lei, pode-se observar que não existia qualquer lei natural que as pudesse proteger e que convenientemente apenas os Estados podiam oferecer proteção legal.

Houve também um "silencioso constrangimento" dos países não totalitários, que de certo modo tornaram possível o holocausto e também fizeram parte de alguma maneira do período de desintegração política, que consequentemente gerou milhares de "apátridas, desterrados, proscritos e indesejados, enquanto o desemprego tornava milhões de outros economicamente supérfluos e socialmente onerosos. " (ARENDT, 1989, p. 498).

Os campos de internamento tornaram-se "solução de rotina”, eram "o único território que o mundo tinha a oferecer aos apátridas" (ARENDT, 1989, p. 318) que eram postos em campos de concentração pelos inimigos e em campos de internamento pelos amigos. Para Arendt o que aconteceu aos apátridas e refugiados especificamente foi que "Não foram privados especificamente de algum direito humano, mas de uma comunidade que lhes garantisse direitos", e deste modo "encontravam-se numa situação de completa anomia.” (RIBAS, 2013, p. 173).

A partir destas reflexões Arendt passa a crer que o ser humano para ter seus direitos humanos resguardados deveria se assegurar em apenas um direito "o direito de nunca ser excluído dos direitos garantidos por sua comunidade [...] e nunca ser privado de sua cidadania." (ARENDT, 1949, p. 36). Para que isso acontecesse de maneira adequada seria necessário, que como os outros direitos, o direito à cidadania fosse acordado pelos próprios seres humanos, com garantias recíprocas, e que os seres humanos se dispusessem a estabelecê-lo. Seria uma tarefa difícil, mas não impossível.

Nós não nascemos iguais: nós nos tornamos iguais como membros de uma coletividade em virtude de uma decisão conjunta que garante a todos direitos iguais. A igualdade não é um dado - ele não é physis, nem resulta de um absoluto transcendente externo à comunidade política. Ela é um construído, elaborado convencionalmente pela ação conjunta dos homens através da organização da comunidade política. Daí a indissolubilidade da relação entre o direito individual do cidadão de autodeterminar-se politicamente, em conjunto com os seus concidadãos, através do exercício de seus direitos políticos, e o direito da comunidade de autodererminar-se, construindo convencionalmente a igualdade. (LAFER, 1988, p. $150)$.

Arendt não ficou muito satisfeita com as tentativas, após o término da Segunda guerra, as quais se propuseram a rever os direitos humanos, afinal a proposta foi constituir uma nova Declaração de Direitos e para ela a nova Declaração não conseguiu estabelecer os direitos necessários com precisão, continuando a confundir os direitos humanos com os direitos dos 
cidadãos. A tentativa da Declaração de direitos para Arendt funciona como que para reatar com a tradição, iniciada na Declaração da Revolução Francesa. Os direitos humanos não foram realmente repensados. É quase que como se o totalitarismo não tivesse existido, algo muito grave, que foi apenas deixado de lado. Com tal precedente é extremamente necessário que se reflita em como reagir.

A proposta de Arendt de um "direito a ter direitos" não chegou a se constituir, mas apresenta-se como uma possibilidade interessante. Arendt imaginou um outro tipo de cidadania, que gera o direito a ter direitos. Assim como os gregos na antiguidade constituíram a pólis, a humanidade constituiria um espaço público onde ninguém ficasse de fora. Quando Arendt aborda sua concepção de cidadania, ela não a concebe do ponto de vista formal, como o direito a pertencer a uma nacionalidade, ou algo que o valha.

O primeiro direito humano é o direito a ter direitos. Isto significa pertencer, pelo vínculo da cidadania, a algum tipo de comunidade juridicamente organizada e viver numa estrutura onde se é julgado por ações e opiniões, por obra do princípio da legalidade. A experiência totalitária é, portanto, comprobatória, no plano empírico, da relevância da cidadania e da liberdade pública enquanto condição de possibilidade, no plano jusfilosófico de asserção da igualdade, uma vez que a sua carência fez com que surgissem milhões de pessoas que haviam perdido seus direitos e que não puderam recuperá-los devido à situação política do mundo, que tornou supérfluos os expulsou da trindade Estado-Povo-Território. (LAFER, 1988, p.154).

A cidadania é a base para o direito a ter direitos e não pode ser como anteriormente, algo dado ou declarado. Ao contrário, deve ser construída em um acordo internacional mútuo com garantias mútuas, para que todos possam usufruir, mesmo estando fora da proteção de seus Estados. Há a necessidade de uma comunidade internacional disposta a garantir o direito a ter direitos. Após o segundo pós-guerra algumas leis foram realizadas em favor dos apátridas, isto não decorre apenas do medo de outro fenômeno totalitário, e sim porque está havendo uma universalização da questão dos refugiados, que antes predominava na Europa.

A existência de seres humanos sem um lugar no mundo aumentou desde o pós-guerra, contribuindo com a situação, que vê tais homens como supérfluos. Celso Lafer explica, a complexidade de se resolver o tema no âmbito internacional, tendo em vista as dificuldades de encontrar um novo lar, para os que perderam o seu.

De fato, expressivo número de refugiados permanece deslocado no mundo, pois: (I) existem sérios obstáculos em muitas partes à sua repatriação voluntária; (II) o país de primeiro asilo - o do asilo temporário - , muito frequentemente, como foi visto acima, é subdesenvolvido e tem limitada capacidade econômica para transformar refugiados em imigrantes; e (III) é difícil encontrar países que absorvam refugiados em virtude dos problemas de toda natureza que têm hoje em dia os Estados para receberem novas e significativas correntes migratórias. (LAFER, 1988, p. 160).

Mesmo diante de tantos empecilhos, a busca por uma reconstrução dos direitos humanos é fundamental. Entende-se que o pensamento de Arendt de um modo original, busca no passado distante elementos para uma reconexão com a realidade. Suas reflexões apontam para uma nova possibilidade para a concretização dos direitos humanos.

O totalitarismo inverteu a concepção tradicional das leis, Arendt retoma a importância da ideia de uma legislação que proteja a humanidade e sua existência. Mas não só a legislação resolveria a situação dos direitos humanos. As leis delimitam o espaço das relações humanas, enquanto que o ter um direito de fato é uma ação.

No governo constitucional, as leis positivas destinam-se a erigir fronteiras e a estabelecer canais de comunicação entre os homens, cuja comunidade é continuamente posta em perigo pelos novos homens que nela nascem. A cada nascimento, um novo começo surge para o mundo, um novo mundo em potencial passa existir. A estabilidade das leis corresponde ao constante movimento de todas as coisas humanas, um movimento que jamais pode cessar enquanto os homens nasçam e morram. As leis circunscrevem cada novo começo e, ao mesmo tempo, asseguram a sua liberdade de movimento, a potencialidade de algo inteiramente novo e imprevisível; os limites das leis positivas são para a existência política do homem o que a memória é para a sua existência histórica: garantem a preexistência de um mundo comum, a realidade de certa continuidade que transcende a duração individual de 
cada geração, absorve todas as novas origens e delas se alimenta. (ARENDT, 1989, p. 517).

A construção legislativa é interessante na proteção dos indivíduos, mas sozinha não resolve a questão dos direitos humanos. É necessária uma ação reiterada de cada geração para organizar-se politicamente e constituir o espaço propício para a cidadania. Apenas o avanço na positivação de leis internacionais, não resolvem o problema, afinal as pessoas que estão fora do âmbito da lei, não tem acesso a legalidade.

Como possibilidade de reconstrução dos direitos humanos Arendt apresenta a ideia da constituição de uma cidadania, como um artifício humano. Tal cidadania, diferente da que necessita de um Estado nacional, essa cidadania seria estabelecida no âmbito internacional, de um modo que cada indivíduo teria como premissa o direito a ter direito, evitando assim que os refugiados e apátridas, por não ter um Estado a quem evocar, fiquem a margem da sociedade. A garantia de cidadania que Arendt fala prevê o não despojamento da humanidade do indivíduo, a não redução deste indivíduo a mera vida biológica. A autora pretende, garantindo a cidadania, que este indivíduo não se torne solitário a ponto de não poder agir junto aos seus pares, e não se isole a ponto de não mais identificar a Terra como seu lar.

Para melhor compreender em que termos Arendt concebe a cidadania, apresenta-se o voto dos ministros Pollak e Warren, contra a expatriação de nacionais nos Estados Unidos. Ambos utilizaram a argumentação de Arendt:

A cidadania é o direito básico do homem, uma vez que é nada menos do que o direito a ter direitos. Tire este bem inestimável e restará um apátrida, humilhado e degradado aos olhos de seus compatriotas. Ele não tem direito a proteção jurídica de nenhuma nação, e nenhuma nação asseverará direitos em seu nome. Sua própria existência está na dependência do Estado em cujas fronteiras ele estiver. Nesse país o expatriado irá presumivelmente gozar, quando muito, apenas direitos limitados e privilégios de estrangeiros, e, como o estrangeiro, estará inclusive sujeito à deportação e, desse modo, privado do direito de afirmar qualquer direitos.

$[\ldots]$

A reflexão de Hannah Arendt sobre a cidadania como o direito a ter direitos, provocada pelos problemas concretos gerados pelo "estado de natureza totalitário", tem como nota, no meu entender, a especificidade da ruptura. Com efeito, não se trata nem da injustiça social, nem da opressão econômica, nem da privação da liberdade, nem de repressão política, que constituem violações dos direitos humanos frequentes na interação entre governantes e governados em regimes tirânicos, autoritários e ditatoriais. De fato, estas violações não são uma novidade. Elas ocorrem dentro de comunidades políticas, exigindo a sua mudança - uma mudança que postula uma adequada distinção entre o público e o privado, como se verá - mas que pode seguir os caminhos do processo de asserção histórica dos direitos humanos como uma "invenção" rastreada acima no capítulo IV.

O que Hannah Arendt estabelece é que o processo de asserção dos direitos humanos, enquanto invenção para convivência coletiva, exige um espaço público. Este é kantianamente uma dimensão transcendental, que fixa as bases e traça os limites da interação política. A este espaço só se tem acesso pleno por meio da cidadania. É por essa razão que, para ela, o primeiro direito humano, do qual derivam todos os demais, é o direito a ter direitos, direitos que a experiência totalitária mostrou que só podem ser exigidos através do acesso pleno à ordem jurídica que apenas a cidadania oferece. (LAFER, 1988, p. $162 / 165)$.

Os migrantes saem de suas casas, deixam seus países muitas vezes por estarem sofrendo tipos de violência e já não possuírem um lugar para estar no mundo. O caminho que percorrem também é permeado por riscos e agressões diversas, quando chegam em países nos quais pensam em se estabelecer, na maioria das vezes são violentados por meio de preconceito e exclusão da vida pública, ou seja, os deslocados vivem uma vida de violência e exclusão.

O período compreendido da primeira grande guerra e a Segunda Guerra Mundial, gerou ao mundo uma categoria de pessoas reconhecidas como apátridas. Conforme já se afirmou neste trabalho, essas pessoas perdiam sua nacionalidade, e eram obrigadas a sair de seus países sem a proteção de qualquer Estado. Este fenômeno onde milhares de pessoas ficaram sem qualquer proteção legal, podendo contar apenas com a solidariedade de poucos despertou o interesse pela reflexão da filósofa Hannah Arendt, contemporânea da segunda guerra mundial, que passou também pela situação de apatrídia, chegando a vivenciar um campo de internamento. Seu pensamento sobre a situação 
dos apátridas, é de enorme importância e pertinência, ainda e especialmente hoje.

Ao desenvolver uma reflexão histórica de como os direitos das minorias étnicas foram suprimidos até chegar ao fenômeno principal que é a perda da nacionalidade e eventualmente a expulsão do próprio país, Hannah Arendt consegue demonstrar uma das maiores fissuras na efetivação dos direitos humanos. A filósofa demonstra o quão importante é o pertencimento do indivíduo a qualquer comunidade. Sem a premissa de pertencimento o indivíduo perde a voz dentro da comunidade e não consegue exercer suas características humanas por excelência, que para Arendt são a ação e o discurso. Tal situação acaba por subtrair a humanidade e o pertencimento do indivíduo que fica à mercê da "boa vontade dos outros", não tendo de fato o reconhecimento de seus direitos nem garantias legais extremamente necessárias para a proteção dos direitos humanos.

Mas além da legalidade, é necessário o essencial, ou seja, a alteridade, reconhecimento do outro como ser humano, merecedor de igual respeito e consideração, dotado de direito a ter direito. E é neste sentido que Arendt crítica os Direitos Humanos, para além do debate e das leis criadas em prol dos refugiados, é necessário o reconhecimento de uma cidadania que não pode ser arrancada dos seres humanos, "o direito a ter direitos" uma premissa para concretização dos direitos humanos. Leis podem e devem ser fabricadas, mas a efetividade dos direitos ocorre apenas no campo da ação política.

\section{REFERÊNCIAS}

ARENDT, Hannah. A condição humana. Tradução de Roberto Raposo. 11. ed. rev. Rio de Janeiro: Forense Universitária, 2010.

Eichmann em Jerusalém / Hannah Arendt; tradução José Rubens Siqueira. - São Paulo: Companhia das Lestras, 1999.

Entre o passado e o futuro. Tradução Mauro w. Barbosa. 5. ed. São Paulo: Editora Perspectiva S.A., 2000.

Origens do Totalitarismo. Tradução de Roberto Raposo. São Paulo: Companhia das Letras, 1989.

. Sobre a revolução. Tradução Denise Bottmann. São Paulo: Companhia das Letras, 2011.

Responsabilidade e Julgamento. São Paulo: Companhia das Letras, 2005.
AGUIAR, Odilio Alves. A questão social em Hannah Arendt. Trans/Form/Ação, São Paulo, v. 27, n. 2, p.7-20. 2004.

BOBBIO, Norberto. A Era dos Direitos. Tradução de Carlos Nelson Coutinho. Nova ed. Rio de Janeiro: Elsevier, 2004.

COMPARATO, Fábio Konder. Fundamento dos Direitos Humanos. Instituto de Estudos Avançados da Universidade de São Paulo, São Paulo, 1997.Texto disponível em http:// www.dhnet.org.br/direitos/anthist/a_pdf/comparato_ fundamentos_dh.pdf. Acesso em: 06 de Agosto de 2017.

CONSTANT, B. Da liberdade dos antigos comparada a dos modernos. Revista de Filosofia Política, Porto Alegre, $n^{\circ} 2$, pp. 9-28, 1985.

CORREIA, A. A vitória da vida sobre a política. Revista Brasileira de Cultura-CULT, São Paulo: Editora Bregantini, n. 129, p.61-63, outubro. 2008.

DOUZINAS, Costas. O fim dos direitos humanos. São Leopoldo: Unisinos, 2009.

FARIA, José Eduardo. A política após a globalização. In: SIMPÓSIO NACIONAL DE HISTÓRIA, 20., 1999, Florianópolis. História: fronteiras. Anais do XX Simpósio da Associação Nacional de História. São Paulo: HumanitasFFLCH-USP/ANPUH, 1999, p. 585-587.

LAFER, Celso. A Reconstrução dos Direitos Humanos: um diálogo com o pensamento de Hannah Arendt. São Paulo: Companhia das Letras, 1988.

MIRANDA, João Irineu de Resende. O Tribunal Penal Internacional frente ao princípio da soberania. Londrina: Eduel, 2011.

NEVES, Marcelo. A Força Simbólica dos Direitos Humanos. Revista Eletrônica de Direito do Estado., Salvador, número 4, out/nov/dez. 2005.

RIBAS, C. M. Apontamentos em torno da ideia de liberdade em Hannah Arendt. O cinquentenário da Declaração Universal de Direitos do Homem. São Paulo: EDUSP, 1999.

Os Direitos Humanos no mundo do animal laborans. Revista de Filosofia Argumentos., Ano 5, no 9 , Fortaleza, jan/jun. 2013. 